\title{
Los recintos fortificados como marco de desarrollo de la cultura castreña en el norte de la península ibérica
}

\author{
Fortified recints and the development of «castreña» culture \\ in the north of iberian peninsula
}

NARCISO SANTOS YANGUAS*

\begin{abstract}
RESUMEN
Los centros de población indígena (castros) y el territorio que les circunda constituyen el ámbito de explicación no sólo del poblamiento de estas comunidades del Norte peninsular sino también de su organización económico-social. Esta base material, que incluye el territorio controlado y explotado por los habitantes de cada uno de los poblados, experimentará algunos cambios en tiempos romanos, dándose paso entonces a su petrificación (edificaciones de piedra).

Las transformaciones de la presencia romana no alteran sustancialmente las estructuras constructivas castreñas, produciéndose sin embargo cambios profundos en la organización de su territorio a través de las civitates.

Este tipo de poblamiento pervive en tiempos romanos en conexión con ciertas formas de organización indígena.
\end{abstract}

PALABRAS CLAVE: Castros, Recintos fortificados, Península Ibérica, civitates.

\section{ABSTRACT}

Centres inhabited by native population (castros) and the territory around them lie at the heart not only of the process that explains how these communities became gradually inhabited, but also of their economic and social organization.

This material basis, which includes the territory controlled and exploited by the inhabitants of each settlement, will undergo some changes in Roman times. It will be precisely then that the buildings will be built in stone.

The changes in Roman times will not on the one hand effect the structures of the "castros", but they will, on the other, transform the organization of the territory, above all by means of the civitates. This type of settlement is connected in Roman times with some given forms of native organization.

KEYWORDS:

Castros, Fortified Recints, Iberian

Peninsula, civitates.

* Dpto. de Historia Antigua. C/ Tte. Alfonso Martínez, s/n. Facultad de Geografía e Historia. Campus de Humanidades. 33011 Oviedo. E-mail: nsantos@ uniovi.es 


\section{INTRODUCCIÓN}

La base material de la cultura castreña cuenta, como punto de referencia, con los centros de hábitat, identificados con los poblados; estos recintos disponían de un territorio circundante, más o menos amplio¹.

De esta manera los recursos propios de cada uno de ellos serían controlados y explotados por parte de sus habitantes ${ }^{2}$, lo que explica, entre otras cosas, la organización social existente en dicho ámbito ${ }^{3}$.

En las páginas siguientes no pretendemos llevar a cabo un análisis completo de la morfología del hábitat castreño del N.0. peninsular en su conjunto ni tampoco del territorio de los astures (ni siquiera del correspondiente a la Asturias actual, aunque nos vaya a servir como punto de referencia) de manera individualizada, aspectos sobre los que existen abundantes trabajos, más logrados sin duda que la síntesis que podríamos ofrecer aquí y que, en cualquier caso, sobrepasarían los objetivos del presente análisis.

Vamos a referirnos, aunque sea de forma somera, al proceso de génesis y formación de dichas comunidades castreñas septentrionales, así como de su poblamiento característico, sin olvidar en ningún momento los factores que intervendrían en su desarrollo histórico ${ }^{5}$.

\section{LA CONFIGURACIÓN DE LAS POBLACIONES CASTREÑAS}

En el proceso de formación de las comunidades castreñas del Norte peninsular en general, y de los astures en particular, el punto de arranque temporal hay que hacerlo remontar, en lo que se refiere a algunos de sus elementos más característicos, a la fase final de la Edad del Bronce ${ }^{6}$.

1 M. Xusto, «Area de visión, topografía e territorialidade: o mundo dos castros», Boletín Auriense 1819 (1988-1989) 23 y ss.

2 Ver, por ejemplo, J. F. Torres, «Silvicultura, recursos forestales y paleoambiente en la economía de la Protohistoria final del Norte peninsular», Kalathos 20-21 (2001-2002), 138 y ss.

${ }^{3}$ M. ${ }^{a}$ D. Fernández-Posse y otros, «Estructura social y territorio en la cultura castreña prerromana», I Congreso de Arqueología Peninsular, Porto 1994, pp. 191 y ss. Cf. igualmente P. S. Wells, "Settlement and Social Systems at the End of the Iron Age", Celtic Chiefdom. Celtic State, Cambridge 1999, pp. 88 yss.

${ }^{4}$ Basta con echar una ojeada, entre otros, a A. Romero Masiá, El hábitat castreño. Asentamiento y arquitectura de los castros del N.O. peninsular, Santiago de Compostela 1976; F. Calo Lourido, A cultura castrexa, Vigo 1993; J. Camino, Los castros marítimos en Asturias, Oviedo 1995; Varios, A cultura castrexa galega a debate, Tuy 1996; A. Fanjul, Los castros de Asturias. Una revisión territorial y funcional, Teverga 2005.

Para más detalles remitimos a los Apéndices de las páginas finales de este trabajo.

${ }^{5}$ E. Carrocera y F. Jordá, "Aproximación al conocimiento del hábitat y territorio castreños», Arqueología espacial 5 (1984), 7 y ss.

6 F. Calo Lourido y X. C. Sierra Rodriguez, "Os orixens do castrexo no Bronce final», Estudos de cultura castrexa e de historia antiga de Galicia, Santiago de Compostela 1983, pp. 19 y ss. 
A este respecto el cuadrante nordoccidental peninsular se vería envuelto en el proceso de penetración hacia el septentrión ibérico de elementos indoeuropeos correspondientes a la segunda oleada de migraciones de dichas poblaciones a partir de los siglos vi-v a.C. ${ }^{7}$.

No iba a ser ésta, sin embargo, sino la tercera de tales migraciones la que incidiría directamente y con mucha mayor fuerza sobre el territorio septentrional de la Península Ibérica ya en una época mucho más avanzada (a partir del siglo III), coincidiendo con la configuración definitiva de la cultura castreña y sus asentamientos de hábitat en tiempos anterromanos ${ }^{8}$.

Frente a lo que creen algunos investigadores ${ }^{9}$, este tipo de aportaciones étnico-culturales parecen haber arrastrado consigo la configuración de «sociedades guerreras» ${ }^{10}$, armadas, que se pelearían por el control de los recursos económicos con que contaba el territorio por ellas habitado (en especial los aprovechamientos mineros y los pastos).

Este hecho influiría sin duda de manera acusada en el surgimiento de los recintos de hábitat fortificados; y ello a pesar de que en la etapa prerromana de la cultura castreña los poblados castreños estarían construidos a base de madera como material fundamental, produciéndose la petrificación de los mismos desde la época de César y/o Augusto ${ }^{11}$.

Se produciría así la llegada a las costas cantábricas de un número impreciso de elementos humanos, entre quienes formarían parte algunos miembros de poblaciones celtizadas o célticas ${ }^{12}$, lo que traería consigo no solo el conocimiento de las técnicas y metalurgia del hierro sino que contribuiría igualmente al proceso de sedentarización de los grupos nómadas.

En el caso de la Meseta Norte estos hechos darían origen a un amplio desarrollo, tanto cuantitativo como cualitativo, de la cultura castreña ${ }^{13}$, evolucionando como consecuencia de ello los sistemas defensivos (murallas, piedras hincadas, fo$\operatorname{sos}^{14}$ ), tal vez con el objetivo de protegerse de los ataques, reales o hipotéticos, de otras poblaciones igualmente de procedencia indoeuropea/ céltica ${ }^{15}$.

Podemos afirmar, por consiguiente, que, desde los momentos finales del siglo Iv a.C., y en especial durante la centuria siguiente, tendría lugar la penetración

7 M. A. de Blas, «La Edad del Bronce», Historia general de Asturias, Gijón 1982, 1, p. 110.

8 J. L. Maya, «El factor indoeuropeo y su influencia en el N.O. de la Península Ibérica», Aquitania 12 (1994), 297 y ss.

9 Por ejemplo F. J. Lomas, Asturia prerromana y altoimperial, Oviedo 1989, p. 30.

${ }_{10}$ Acerca de esta cuestión remitimos, entre otros, a P. Ciprés, Guerra y sociedad en la Hispania indoeuropea, Vitoria 1993.

11 C. A. Ferreira de Almeida, "Cultura castreja. Evoluçao e problematica», Arqueologia 8 (1983), 70-71.

12 F. Arias Vilas, «La cultura castrexa en Galicia», MHA 6 (1985), 16.

13 Más detalles en J. Maluquer, «El poblamiento prerromano en la Meseta del Duero», Segovia y la arqueología romana, Barcelona 1977, pp. 28-29.

14 Ver, entre otros, A. Esparza, «Nuevos castros con piedras hincadas en el borde occidental de la Meseta", Actas do Seminario de Arqueologia do Noroeste peninsular, Guimaraes 1980, 2, pp. 71 y ss.

${ }^{15} \mathrm{~J}$. L. Avello, «Panorama arqueológico de los astures cismontanos en la actual provincia de León», MHA 7 (1986), 7 y ss. 
más intensa de elementos indoeuropeos, matizados por un cierto celtismo, que incidirían directamente sobre las regiones septentrionales hispanas ${ }^{16}$.

A consecuencia de ello se daría paso en dicho contexto geográfico a un cierto proceso de celtización, que aflora con bastante claridad en los aspectos culturales, y de forma no tan evidente en los lingüísticos ${ }^{17}$, pero que en cualquier caso nada tiene que ver con la presencia masiva (y configurando grupos de población independiente provenientes del exterior) de elementos exclusivamente celtas.

Las influencias materiales y culturales más evidentes en el caso de la Asturias prerromana quizás sean las que afloran en el poblado castreño de Caravia ${ }^{18}$, mientras que, entre las poblaciones astures de la región leonesa, es posible detectar igualmente indicios de este tipo de contactos y vinculaciones ${ }^{19}$.

Tales conexiones, tanto étnicas como culturales, con la Meseta del Duero se harían más intensas a lo largo de las dos centurias anteriores a nuestra era, momento al que corresponde un grupo de monedas acuñadas en las cecas del valle del Ebro y aparecidas en los recintos poblacionales del N.O. peninsular ${ }^{20}$.

En este sentido en territorio asturiano se han descubierto fortuita y esporádicamente algunas de ellas, como las acuñaciones de Aregorada encontradas en Gúa, o el tesoro de monedas de Segóbriga halladas en el Coto de la Buena Madre, en ambos casos en el concejo de Somiedo ${ }^{21}$.

Llegados a este punto nos encontramos ante un controvertido tema para los investigadores de la cultura castreña del N.O. peninsular ibérico: ¿hay que hablar realmente de penetraciones celtas en la zona septentrional hispana o hemos de referirnos más bien a influencias y conexiones de carácter cultural?.

Historiadores románticos y nacionalistas no dudan en ligar lo castreño con lo celta, constituyendo para ellos el sustrato celta el elemento más característico de dicha cultura ${ }^{22}$.

${ }^{16}$ Como ya había observado perfectamente J. Martínez Santaolalla (Esquema paletnológico de la Península hispánica, Madrid 1946, 2, pp. 77 y ss.).

Para más detalles sobre dichas influencias, en este caso desde el punto de vista estrictamente constructivo, remitimos a A. García y Bellido, «Orígenes de la casa redonda de la cultura castreña del N.O. de la Península», RG 81 (1971), 3 y ss. o a E. Carrocera y M. de la Rasilla, "Análisis arqueográfico e interpretación histórica de una cabaña castreña», Boletín Brigantium n. ${ }^{\circ} 6$ (1989-1990), 65 y ss.

${ }^{17} \mathrm{~F}$. J. Lomas, Asturia prerromana y altoimperial, pp. 34-38.

${ }^{18}$ A. del Llano, El libro de Caravia, Oviedo 1919. Una explicación profunda de esta cuestión la encontramos en J. Camino, «Algunos comentarios sobre las pautas territoriales y sociales de los castros del Oriente de Asturias», Los poblados fortificados del N.O. de la Península Ibérica, Navia 2002, pp. 139 y ss.

19 C. Morán, Por tierras de León. Historia, costumbres, monumentos, leyendas, filosofía y arte, Salamanca 1952, pp. 111-113.

20 J. L. Maya, «La cultura castreña asturiana: de los orígenes a la romanización», Indigenismo y romanización en el conventus Asturum, Madrid-Oviedo 1983, p. 21.

21 M. Menéndez García, «Monedas ibéricas en Asturias», BCPMOviedo 2 (1959), 211-213.

Un exponente de estos contactos se observa en la mención de Estrabón al hecho de que las poblaciones montañesas del Norte peninsular utilizaban láminas de plata recortada en lugar de monedas para sus intercambios comerciales (Geografía 3.3.7).

22 Ver, como exponente, las palabras de los autores que firman el artículo titulado «Panorámica general sobre la cultura castrexa», Estudos de cultura castrexa e de historia antiga de Galicia, p. 90. 
Esta postura tradicional ha venido siendo defendida por una gran mayoría del colectivo de historiadores hasta hace escasos años, a pesar de que se trate de un planteamiento cada vez más en declive ${ }^{23}$.

Frente a ello otros estudiosos del mundo castreño niegan que la presencia de estos grupos de penetración indoeuropeos en las regiones septentrionales ibéricas obedeciese exclusivamente a una influencia céltica, o cuando menos que se produjesen de forma masiva, defendiendo en contrapartida como primordial la importancia de lo autóctono en el caso de la cultura de los castros ${ }^{24}$.

Y ello aunque no podamos excluir un cierto proceso de celtización, que tal vez tendría lugar ya en una época bastante tardía (la hipótesis más plausible en el estado actual de nuestros conocimientos).

Al igual que piensa G. Pereira ${ }^{25}$ consideramos que, en el marco de este debate, el tema del celtismo no resulta algo esencial o prioritario (como venía sucediendo en las últimas décadas), puesto que los yacimientos arqueológicos no nos han proporcionado todavía restos materiales suficientes en número ni claros en su tipología para poder ser catalogados como celtas en el sentido estricto (y menos aún desde el punto de vista étnico).

Por consiguiente el celtismo que arraigaría en estas regiones del N.O. peninsular no se debería a aportaciones étnicas de extraordinario relieve (abundantes y numerosos grupos de gentes) sino más bien a simples refracciones culturales, que posiblemente haya que vincular con las relaciones galaico-galas (cultura de La Tène) con anterioridad al siglo $\mathrm{v}^{26} \mathrm{o}$, incluso, con la afluencia de elementos de origen o raíz celta provenientes de la Meseta ya en tiempos romanos.

\section{CRONOLOGÍA DEL HÁBITAT CASTREÑO}

La cuestión referida a las diferentes fases o períodos que abarca la cultura castreña entre las poblaciones septentrionales hispanas continúa todavía sin cerrar ${ }^{27}$.

Partimos del hecho de que el momento de verdadero arraigo de la cultura castreña prerromana en el caso de Asturias no parece haberse iniciado hasta bien avanzado el siglo III, prolongándose al menos a lo largo de las dos últimas centurias anteriores a nuestra era $^{28}$.

${ }^{23}$ Ver, entre otros, F. López Cuevillas, La civilización céltica, Santiago de Compostela, 1953, p. 88, y J. M. González, Antiguos pobladores de Asturias, Salinas 1976, pp. 96-97.

${ }_{24}$ Opinión que arranca ya de A. García y Bellido («El castro de Coaña (Asturias)», RG 50 (1940), 308-310). Ver igualmente C. Parcero, «Tres para dos. Las formas de poblamiento en la Edad del Hierro del Noroeste ibérico», Trabajos de Prehistoria 57 (2000), 75 y ss.

25 «Limiar», Estudos de cultura castrexa e de historia antiga de Galicia, pp. 8-9.

26 J. Maluquer, «El mundo indígena del N.O. hispánico antes de la llegada romana», Actas del Coloquio sobre el bimilenario de Lugo, Lugo 1977, p. 13.

27 Ver, por ejemplo, para el caso galaico F. Arias Vilas, «Las fases de la cultura castreña en Galicia: un debate abierto», Los poblados fortificados del N.O. de la Península Ibérica, pp. 127 y ss.

28 J. L. Maya, «La cultura castreña asturiana: de los orígenes a la romanización», p. 20. 
Este período histórico coincide, además, con la época en que comenzarían a difundirse las técnicas, utensilios e instrumental de hierro, a pesar de que predominen todavía los útiles de bronce (incluso en tiempos romanos los objetos elaborados con este metal serían muy abundantes).

Algo similar sucedería en el área cultural galaico-portuguesa, cuyo período de máxima expansión en tiempos prerromanos se extendería entre los siglos IV y II a.C., siendo calificado por algunos investigadores como etapa castreña clásica ${ }^{29}$.

Se identificaría por tanto con la etapa en que surgirían y cobrarían fuerza la mayor parte de los recintos castreños (a excepción de los que tendrían su origen en época romana como consecuencia de la puesta en explotación intensiva de los recursos mineros del oro), al tiempo que la metalurgia y la orfebrería conocen una época de gran actividad ${ }^{30}$.

En este contexto las incursiones militares llevadas a cabo sobre el territorio galaico por parte de Décimo Junio Bruto y Julio César quizás frenarían, al menos parcialmente, esta fase de esplendor, aunque más bien dichas actividades pudieron conectarse con un proceso distinto, que se iniciaría entonces y que parece manifestarse más claramente en la época de Augusto: nos estamos refiriendo a la petrificación de las construcciones poblacionales de los recintos castreños ${ }^{31}$.

Este período final prerromano se correspondería con la fase típicamente castreña, siendo la que definiría en realidad a dicha cultura, al menos en lo que concierne a la construcción y a la organización (interna y externa) del poblado, así como al aprovechamiento de los recursos económicos de su entorno.

Por lo que concierne a la cronología correspondiente a la cultura castreña del Noroeste peninsular en general podemos seguir las etapas propuestas hace ya un par de décadas por C.A.Ferreira ${ }^{32}$, para quien el período castreño medio se identifica con los años posteriores a la invasión-reconocimiento (campaña militar) de César en el año 61-60 a.C., momento a partir del cual el área castreña meridional experimenta un gran dinamismo.

Desde ese momento los poblados castreños comenzarían a estar formados por edificaciones de piedra, a pesar de que las hiladas horizontales de tendencia isodámica únicamente aparecerán perfectamente utilizadas a partir de la época de los Flavios.

En cuanto al período castreño reciente lo identifica dicho autor con el hecho de que, a partir de Augusto, se hacen presentes los primeros síntomas de decoración de los elementos constructivos (más acusados en el área meridional), al tiempo

${ }^{29}$ Ver, por ejemplo, A. C. Ferreira da Silva, «A cultura castreja no Noroeste de Portugal: hábitat e cronologias», Portugalia 4-5 (1983-1984), 121 y ss.

$30 \mathrm{M}^{\text {a }}$ D. Fernández-Posse y otros, «Espacio y metalurgia en la cultura castreña: la zona arqueológica de Las Médulas», Trabajos de Prehistoria 50 (1993), 197 y ss.

31 Para ahondar en estos temas remitimos a N. Santos, «La conquista romana de Galicia», Boletín Brigantium, n. ${ }^{\circ} 3$ (1982), 75 y ss.

32 «Cultura castreja. Evoluçao e problemática», pp. 70 y ss. 
que en muchos de los edificios el aparejo (granítico y poligonal) y su colocación "denteada» alcanzan una cierta regularidad, que llega al reticulado ${ }^{33}$.

Por su parte el período castreño final se iniciaría, al menos en lo que respecta al área meridional de la cultura castreña, a partir de la época de los Flavios, mientras que en la zona Norte (más septentrional) solo se produciría algunos años (tal vez décadas) después ${ }^{34}$.

Desde el punto de vista técnico la innovación más significativa consistiría sin duda en la construcción rápida de las edificaciones, optando por hiladas de tendencia horizontal y por la colocación de las piedras en los muros en una posición acorde con su centro de gravedad ${ }^{35}$.

Por consiguiente, en todo el cuadrante nordoccidental hispano en general, y en particular en la zona más próxima al territorio controlado ya administrativamente por Roma, los habitantes de los recintos castreños dotarían a dichos poblados de un sistema defensivo cada vez más complicado, reforzándose y ampliándose no solo los fosos sino también las murallas, así como otros elementos «defensivos» (contrafosos, terrazas...), ante la amenaza que podía suponer la presencia de los ejércitos romanos, o al menos de algunos destacamentos (vexillationes) de los mismos ${ }^{36}$.

A este respecto no debemos olvidar que, en los años previos al desarrollo de los enfrentamientos bélicos en el Norte hispano, los romanos llevarían a cabo (quizás con esos objetivos) toda una serie de campañas, algunas de ellas de tanteo sin duda, contra las poblaciones septentrionales de la Península lbérica de acuerdo con los Acta Triumphalia ${ }^{37}$.

\section{EL POBLAMIENTO CASTREÑO EN ASTURIAS}

Para comprender el alcance de las guerras astur-cántabras y su incidencia en el hábitat del territorio asturiano en época castreña se hace preciso sintetizar los aspectos fundamentales del marco poblacional correspondiente a las gentes de dicho territorio, así como las características constructivas de los recintos fortificados ${ }^{38}$.

La configuración definitiva de los centros de población en dicho contexto territorial tendría lugar desde finales del siglo IV, coincidiendo con las aportaciones ét-

${ }^{33}$ En el territorio portugués hace su aparición un urbanismo de tendencia ortogonal, como en Sanfins por ejemplo, donde las casas se estructuran en pequeños conjuntos o barrios, que apenas superan una organización de nivel familiar.

34 C. A. Ferreira, «Cultura castreja. Evoluçao e problematica», pp. 72-73.

35 La multiplicación del número de poblados a partir del momento de las guerras astur-cántabras y su localización motivada por intereses agrícolas parece indiscutible en la región galaico-portuguesa.

36 J. L. Maya, «La cultura castreña asturiana: su etapa romano-provincial», Lancia 1 (1983), 222.

37 N. Santos, El ejército romano y la romanización de los astures, Oviedo, 1981, p. 18.

38 Que sin duda se iban a ver alteradas, al menos en parte, en tiempos romanos como consecuencia de las nuevas actividades económicas (fundamentalmente mineras pero también agrarias). 
nicas del último reflujo de las invasiones indoeuropeas, tras desplazarse por la Meseta Norte y que sin duda acarrearían cambios profundos en la región ${ }^{39}$.

De cualquier forma los materiales utilizados en la construcción del caserío correspondiente a dichos núcleos de hábitat serían básicamente de madera, pudiéndose fijar el paso al empleo del material pétreo en dichas actividades ya en las décadas finales del siglo I a.C.

Con respecto a la ubicación de los poblados resulta evidente que la elección del lugar se realizaba por lo general teniendo en cuenta las elevaciones montañosas enclavadas en las zonas medias o bajas de los valles fluviales ${ }^{40}$.

Este tipo de establecimientos de población dispondría de unas condiciones naturales perfectamente adecuadas a la defensa y control del territorio que les correspondía y explotaban, es decir se trataba de asentamientos estratégicos, muy aptos para funciones de tipo defensivo ${ }^{41}$.

Por su parte la constante preocupación por los objetivos de defensa haría que los poblados castreños de los astures, al igual que todos los correspondientes a las poblaciones del Noroeste peninsular, constituyeran recintos fortificados, entre cuyos elementos más destacados se encontraban los fosos, terraplenes o taludes, murallas y torres de vigilancia, combinados de una forma distinta en cada caso ${ }^{42}$.

Los asentamientos poblacionales de los astures contaban por lo general con dimensiones de carácter reducido, hecho que vendría exigido en buena medida por las escasas condiciones de habitabilidad que dichos enclaves territoriales presentaban, a lo que hemos de añadir además motivos estrictamente demográficos ${ }^{43}$.

39 Entre ellos la introducción de nuevas formas constructivas, técnicas agrícolas más avanzadas, los primeros objetos de hierro..., a pesar de que se trataría de un proceso lento y muy tardío.

40 Acerca de las condiciones topográficas, naturales y humanas de dichos enclaves ver, por ejemplo, Estrabón (Geografía 3.4.13):

«Me parece que quienes han contado más de 1.000 ciudades lo han hecho a causa de asignar el nombre de tales a grandes aldeas, puesto que la naturaleza del país no se muestra apta para dar vida a un gran número de centros urbanos, aya que resulta extremadamente mísera, de una situación excéntrica y de un aspecto inculto.

Por otra parte, ni el tipo de vida de sus habitantes ni sus actividades (a excepción de las ciudades ubicadas en la costa del Mediterráneo) dan pié para ello.

Los habitantes de las aldeas son salvajes, y también lo son la mayoría de los iberos; los mismos centros urbanos no pueden ejercer un influjo civilizador cuando la mayor parte de la población vive en los bosques y amenaza la tranquilidad de sus vecinos».

41 A. Romero Masiá, El hábitat castreño. Asentamiento y arquitectura de los castros del N.O. peninsular, pp. 17 y ss.

42 Tal vez estos elementos no tendrían tanto un carácter defensivo (que irían perdiendo con el paso del tiempo) cuanto erigirse en exponentes de un dominio político-social sobre los poblados cercanos (elemento de jerarquización).

43 Es frecuente el hecho de que las dimensiones de los recintos castreños sean mayores en aquellas zonas en las que su número es más escaso, al tiempo que a la mayor abundancia de los mismos parecen corresponder poblados de dimensiones mucho más reducidas.

Para el caso galaico ver, entre otros, X. Carballo, «Espacio e povoamento castrexo de Galiza», Concepcións espaciais e estratexias na historia de Galicia, Santiago de Compostela 1993, pp. 55 y ss., y «O espacio na cultura castrexa galega», A cultura castrexa galega a debate, Tuy 1996, pp. 105 y ss. 
Por lo que respecta al emplazamiento (ubicación) de tales centros de hábitat, en primer lugar hay que decir que se hallaban dispersos por todo el territorio asturiano apto para el desarrollo de actividades ganaderas y agrícolas (más bien de recolección, economía predatoria y/o adquisición simple en muchos casos, al menos durante la primera fase de la cultura castreña prerromana), así como de un modo de vida sedentario ${ }^{44}$.

A pesar de ello nunca llegaría a existir uniformidad (ni étnica ni cultural) en Asturias durante los períodos de la historia castreña: en este sentido han aparecido materiales en recintos poblacionales del centro-oriente de Asturias que ofrecen una conexión más clara con otros correspondientes a los grandes centros de hábitat de la Meseta (Miraveche o Monte Bernorio) que con los de la cultura castreña del Noroeste peninsular propiamente dicha.

Como indicativos de ambas áreas culturales contamos, por una parte, con el poblado de San Chuis de Allande ${ }^{45}$, típico de lo que se conoce como cultura castreña del cuadrante nordoccidental hispano (al igual que el de Coaña y muchos más), y por otro con el de Caravia, ubicado en la región oriental-central de Asturias, donde se manifiesta en toda su evidencia la influencia del Norte de la Meseta $^{46}$.

Además de la función defensiva de todo recinto castreño, que en buena medida cumplirían las condiciones naturales de su emplazamiento, hay que destacar las estructuras construidas intencionadamente con tales objetivos.

En este contexto la conformación de fosos, que rodeaban total o parcialmente el perímetro de los núcleos de población, implicaría simultáneamente la presencia de taludes, rematados o no a su vez por una muralla o parapeto ${ }^{47}$.

De acuerdo con el emplazamiento de muchos de estos centros de población las corrientes fluviales que les circundaban cumplirían las funciones de fosos naturales, complementándose dicha labor con otros de carácter artificial en los lugares de más fácil acceso.

En cualquier caso los fosos constituyen uno de los elementos más frecuentes y simples de los asentamientos castreños, tanto si estaban excavados en la tierra como si lo eran en la roca ${ }^{48}$; la profundidad de dichos fosos no sería uniforme sino variable (el de Mohías, por ejemplo, oscilaba entre los 3 y $4 \mathrm{~m}$ ).

Muchas veces dichos elementos se nos presentan unidos, con vistas sin duda a una mejor tarea defensiva, a murallas o parapetos; estos últimos podían alcanzar

\footnotetext{
44 Acerca de su distribución por el suelo de la actual Asturias remitimos a S. Ríos y C. García de Castro, Asturias castreña, Gijón 1998, pp. 24-27 (véase Apéndice final).

${ }^{45}$ F. Jordá y otros, «El castro asturiano de San Chuis», Revista de Arqueología, 95 (1989), 38 y ss.

46 A. del Llano, Bellezas de Asturias, Oviedo, 1928, pp. 113-116.

47 Para ampliar estas referencias remitimos a N. Santos, «Introducción al estudio del arte castreño en Asturias», BIDEA, n. os 109-110 (1983), 382.

48 El caso más sobresaliente en Asturias es el de Mohías, en el concejo de Coaña, que en algunos puntos parece sobrepasar los $10 \mathrm{~m}$ de anchura, y que cuenta con una longitud de un centenar de metros.
} 
alturas superiores a $10 \mathrm{~m}$, empleándose en su construcción y en la de las murallas los materiales provenientes de la configuración de los fosos (pizarra o tierra) ${ }^{49}$.

Por su parte las murallas, que constituían el elemento más completo y eficaz de la defensa de dichos asentamientos, podían alcanzar alturas y espesores considerables (de hasta $3 \mathrm{~m}$ o más), así como un desarrollo completo de su trazado en torno al perímetro de los castros, como se observa perfectamente en Coaña ${ }^{50}$.

Como aparejo de dichas murallas los materiales de cada zona contribuirían a una primera diferenciación: así los recintos castreños de la región occidental, en especial Pendia, Coaña, La Escrita, Arancedo, Mohías... ${ }^{51}$ nos ofrecen en todas sus construcciones, tanto defensivas como habitacionales, un tipo de aparejo de hiladas horizontales elaborado con lajas, aprovechando sin duda la abundancia de pizarras y esquistos existentes en la zona.

En otras ocasiones lo que encontramos es mampostería ajustada en seco o bien a base de fragmentos de dimensiones más reducidas y acumulación de tierra, mientras que, en casos más aislados, existe un aparejo de tipo poligonal en zonas en las que se da predominio de otros materiales, como la cuarcita por ejemplo ${ }^{52}$.

Sin embargo, no sólo los fosos sino también las murallas acogerían con frecuencia a una serie de elementos defensivos considerados adicionales, como bastiones y refuerzos constructivos (o bien los torreones defensivos), tanto si se encontraban aislados como ligados a la muralla ${ }^{53}$, o los antecastros y terrazas fortificadas, enclavados fuera del recinto principal ${ }^{54}$.

En cualquier caso la complejidad de tales estructuras defensivas se acentuaba en los lugares de acceso a dichos centros de población, en los que a menudo fosos, terraplenes, baluartes o parapetos se hallan interconexionados con la finalidad de que la entrada a los mismos no fuese directa ${ }^{55}$.

49 Más detalles sobre estas cuestiones en C. Parcero, «Variaciones en la función y el sentido de la fortificación a lo largo de la Edad del Hierro en el N.O. de la Península Ibérica», Encuentro de jóvenes investigadores sobre Bronce final y Hierro en la Península Ibérica, Salamanca 2003, pp. 1 y ss.

50 Para más detalles ver F. Jordá, Guía del Castrillón de Coaña (Asturias), Salamanca 1969.

51 Ver a este respecto, entre otros, J. M. Fernández Buelta, «Castro de La Escrita o de Ríu de Castro, Boal», BIDEA, n. 8 (1949), 121 y ss.

52 Los lienzos de algunas de tales murallas no eran corridos sino que se hallaban compartimentados, siendo los ejemplos más representativos los de la Campa Torres o San Chuis de Allande entre otros.

La finalidad de una construcción de este tipo obedecería tal vez a que la caída de una parte de la muralla no arrastrase al resto de la misma. Cf. J. Camino, «Las murallas compartimentadas en los castros de Asturias: bases para un debate», AEA 73 (2000), 27 y ss.

53 El poblado de Mohías nos presenta ejemplos claros de todo ello.

54 X. Carballo, «A xustaposición de elementos defensivos nos castros como un factor de cronoloxía relativa», Boletín Brigantium, n. ${ }^{\circ} 4$ (1983), 205-208.

55 Los bastiones o baluartes solían consistir en un simple ensanchamiento de las propias murallas. Cf. A. García y Bellido, «El castro de Coaña (Asturias)», Investigación y Progreso 14 (1943), 65 y ss. 


\section{ORGANIZACIÓN DE UN RECINTO DE HÁBITAT}

La distribución del espacio habitado en cada enclave de población castreña suele presentar, como elementos comunes, la adaptación a las condiciones topográficas del asentamiento y la falta de un urbanismo de tipo geométrico como eje central con vistas a un desarrollo de la construcción de viviendas acorde con la disponibilidad del suelo.

En este contexto las divisiones internas de los poblados son conocidas como barrios, siendo sus dimensiones muy variables y sin poder asegurar que correspondan a ningún grupo social u organización gentilicia concreta ${ }^{56}$.

Por su parte la tendencia a la construcción de paredes curvas en las edificaciones de tipo doméstico producirá que, al no apoyarse unas en otras (ni contar por tanto con muros comunes y/o paredes medianeras), no exista alineación de las mismas, de un modo comparable a lo que sucede en el caso de los castros meseteños (Las Cogotas, Sanchorreja...), en los que las estructuras de planta cuadrangular con paredes medianeras desembocarán en alineación de edificios en calles rectilíneas, haciendo posible de esa manera una división geométrica del espacio ${ }^{57}$.

Entre los denominados «barrios» se descubren ciertos espacios abiertos, que constituirían plazoletas, o bien calles de trazado irregular y que configurarían los caminos de comunicación en el interior de cada poblado ${ }^{58}$.

A este respecto Coaña constituye un ejemplo evidente de la existencia de calles de trazado irregular, pese a lo cual contaban con una especie de enlosado muy bien dispuesto e, incluso, con aceras en una de las partes del poblado, así como canalizaciones de agua en callejuelas revestidas y cubiertas por lajas de pizarra, aunque no debemos olvidar que este tipo de urbanismo (o semiurbanismo) correspondería ya a los años de presencia romana en la región.

Las viviendas y edificios principales de estos poblados castreños nos presentan a menudo pequeñas construcciones adosadas (anejos), cuyas estructuras y objetivos parecen haber sido muy dispares:

- se podía tratar de una especie de vestíbulos de, tanto de paredes rectas como curvas,

- o bien de locales de ampliación del reducido espacio de las viviendas,

- o añadidos laterales, en cuyo caso parecen relacionarse con una hipotética finalidad de almacenamiento (agua, cereales, comida, gramíneas, frutos secos, herramientas agrícolas...),

- o incluso reductos destinados a la recogida de ganado menor y/o aves ${ }^{59}$.

${ }^{56}$ Historia general de Asturias 1, pp. 113 y ss.

$57 \mathrm{Y}$ en consecuencia la aparición de un cierto urbanismo. Cf. A. Romero Masiá, El hábitat castreño, pp. 49 y ss.

${ }_{58}$ En algunas ocasiones estas calles parecen haber estado total o parcialmente pavimentadas (sin duda ya en la historia de dichos poblados en época romana). Cf. X. Carballo, "Os castros galegos: espacio e arquitectura", Gallaecia, 14-15 (1996), 309 y ss.

59 A. García y Bellido, «El castro de Coaña (Asturias) y algunas notas sobre el posible origen de esta cultura», AEA 45 (1950-1951), 288 y ss. 
De cualquier forma la superficie de tales viviendas (y de los edificios en general) era reducida, en especial las de planta circular, cuyo diámetro no sobrepasaba los $6 \mathrm{~m}$.

En este sentido ni éstas ni las cuadrangulares presentan tabiques separadores en su interior, por lo que no existían o estaban elaborados con materiales poco duraderos (madera sobre todo).

Únicamente algunas de ellas llegarían a alcanzar tamaños excepcionales, como sucede por ejemplo en algunos ejemplos de Coaña60, lo que nos permite pensar que habrían sido edificadas con objetivos sociales más amplios (para actividades o servicios comunales).

La altura de los muros de las edificaciones se hallaría en torno a los dos metros de acuerdo con lo que se desprende del material de derribo almacenado en la caída de algunas edificaciones de Mohías y de la parte de la pared que áun ha sido posible rescatar en la excavación ${ }^{61}$.

Sin embargo, ello no quiere decir que, como casos especiales, no hallemos también alturas superiores, como por ejemplo el muro de una construcción de Coaña que cuenta con una elevación de hasta 4-5 m.

En todos las ocasiones las paredes de tales viviendas ofrecen escasos vanos, muy frecuentemente solo las puertas, puesto que no se ha podido comprobar la existencia de ventanas en las mismas.

Además, en este mismo sentido, ciertas casas de Coaña y Mohías presentan dos entradas de acceso, cerradas con puertas de madera, mientras que otras tienen muros conservados a medio metro del suelo sin ningún vano ${ }^{62}$.

Por su parte las puertas consistirían en hojas sencillas de madera, ya que en ejemplos muy contados, y todos ellos fuera de Asturias, se han descubierto buenas piezas de umbrales, jambas y dinteles en piedra, algunos de ellos con decoraciones geométricas ${ }^{63}$.

Más difícil resulta precisar el sistema de cubrición de las viviendas: el hallazgo, en emplazamientos de hábitat de regiones castreñas fuera de Asturias, de trozos de barro unidos a hojas y cañas en el interior de las edificaciones ha permitido suponer que existirían techumbres formadas con vegetales recubiertos de barro para impermeabilizar ${ }^{64}$.

60 F. Jordá, Guía del Castrillón de Coaña (Asturias), p. 6.

61 Estas mediciones fueron llevadas a cabo personalmente en el verano del año 1982 en compañía del Dr. González-Tablas de la Universidad de Salamanca.

62 Probablemente se accedía a ellas mediante escaleras interiores y exteriores, bien de piedra bien de madera.

63 Ver, entre otros, M. Cardozo, «Algunas observaciones sobre el arte ornamental de los castros del Noroeste de la Península», IV CASE, Cartagena 1949, pp. 345 y ss.

64 Con el fin de sustentar estas cubiertas o tejados, similares a los de las pallozas de nuestros días, se utilizarían soportes centrales de madera u otros procedimientos similares. 
La cimentación de los edificios era muy escasa, siendo la mampostería el aparejo fundamental; junto a ello la pavimentación más común estaba constituida por tierra batida o pisada, aunque en ocasiones aparece la roca viva, y en casos muy aislados se han descubierto enlosados de piedra labrada, como en Arancedo o en Mohías, ya en una etapa plenamente romana.

Con el objetivo de evitar humedades en el interior de las viviendas se elevaban los pavimentos con relación al nivel exterior del poblado o se excavaban canales de desagüe, que evitarían el estancamiento y filtración de las aguas residuales y de lluvia.

Uno de los elementos auxiliares más sobresalientes de las viviendas castreñas lo configurarían sin duda los hogares; entre ellos hemos de destacar en primer lugar los de dimensiones bastante amplias del castro de Mohías ${ }^{65}$, elaborados a base de cantos rodados bordeados de pizarra y barro, así como los formados por lajas, como en Pendia.

Otra característica igualmente destacada la constituyen los bancos interiores corridos, adosados a las paredes de las viviendas (en Coaña y San Chuis existen todavía algunos restos), que corroboran el testimonio del geógrafo Estrabón ${ }^{66}$ en el sentido de que los habitantes de los castros realizaban sus comidas reclinados en ellos ${ }^{67}$.

De la misma manera en el interior de las casas de los poblados castreños de la Asturias occidental encontramos a menudo bloques o piedras de granito que presentan varias cazoletas (por lo general entre dos y cuatro) y que por su situación en el conjunto de las viviendas y su proximidad a los hogares deben ser interpretados como instrumentos de carácter utilitario.

Su finalidad parece centrarse en haber servido como elementos de molturación de bellotas, cereales y otras gramíneas para la elaboración de harina ${ }^{68}$.

\section{LOS POBLADOS ASTUR-ROMANOS}

En cuanto al hábitat y poblamiento romanos en el territorio ocupado por las poblaciones astures hay que destacar que, al igual que sucede en otras regiones sep-

\footnotetext{
65 J. Martínez, "Castro de Mohías», BIDEA 1971, pp. 351 y ss. Cf. igualmente A. Romero Masiá, El hábitat castreño, pp. 88 y ss.

66 Geografía 3.3.7.: "Comen sentados sobre bancos construidos alrededor de las paredes, alineándose en ellos de acuerdo con sus edades y dignidades; los alimentos se hacen pasar de mano en mano. Mientras beben los hombres danzan al son de las flautas y trompetas, saltando en alto y cayendo arrodillados...".

${ }^{67}$ Servían para denotar la presencia de una organización socio-política en el marco de estas agrupaciones gentilicias (signo de jerarquización en el seno de dichas comunidades).

68 Los rebordes de dichas piezas impedirían el derrame de los productos resultantes de ese machacado (destinado a la fabricación de tortas de pan o algo similar). Para más detalles remitimos a N. Santos, "Significado de las piedras de cazoletas halladas en los castros asturianos", BIDEA, n. ${ }^{\circ} 112$ (1984), 3 y ss.
} 
tentrionales hispanas, resulta evidente la relación entre el poblamiento de época romana y el propio de las fases históricas anteriores ${ }^{69}$.

Por desgracia no se han producido en este campo avances tan significativos como los que han tenido lugar en otras regiones o provincias del Imperio; este hecho se ha visto frenado sobre todo por no poder contrastar los datos de las fuentes escritas con los resultados de las excavaciones arqueológicas (sumamente débiles) ni con el descubrimiento de monumentos epigráficos de gran valor ${ }^{70}$, que en el territorio asturiano se han llevado a cabo de manera casual y nunca dentro de un contexto arqueológico bien definido.

En el suelo correspondiente a las provincias romanas en que se ha avanzado más en esta dirección se ha hecho posible la identificación de las civitates antiguas con centros de poblamiento actuales, pudiéndose constatar así la continuidad del hábitat de época romana con respecto a los períodos anteriores, llegando a descifrar la posible existencia de una organización de dicho poblamiento en torno a las civitates $^{71}$.

La línea de investigación referente al poblamiento antiguo de época castreña (tanto prerromano como romano) en el territorio asturiano ha de centrarse en estos aspectos para poder llegar a obtener unos resultados más completos.

Por ello la puesta en marcha de análisis microespaciales (concejos en el caso asturiano, o incluso aún menores, como las distintas cuencas hidrográficas en el marco de cada una de dichas circunscripciones administrativas) nos va a permitir establecer sin duda la jerarquización existente en cuanto al poblamiento antiguo, apenas vislumbrada en la documentación escrita y tampoco clara en el caso de los reducidos centros de hábitat excavados ${ }^{72}$.

En conexión con los diferentes colectivos integrantes de la mano de obra utilizada en los aprovechamientos mineros nos encontramos igualmente con el problema suscitado por los lugares de alojamiento de la misma.

69 Ver, por ejemplo, J. Santos, «Conquista y ordenación del territorio de Álava por los romanos en época altoimperial», La formación de Álava. 650 aniversario del Pacto de Arriaga (1332-1982), Vitoria 1984, pp. 447 y ss.

70 Casi nulos en los últimos tiempos si exceptuamos la inscripción descubierta en Arganza (Tineo), que parece demostrar la existencia de la civitas Paesicorum [A. García Linares y N. Santos, «Nueva lápida romana hallada en Arganza (Tineo-Asturias)», MHA 10 (1989), 151 y ss.] o alguna dedicatoria a los Lares Viales...[véase, por ejemplo, R. Cid, P. García y A. Pedregal, «Lucus Asturum y un ara inédita a los Lares Viales en Lugo de Llanera (Asturias)», Gallaecia, 13 (1994), 113 y ss.].

71 Los avances resultan evidentes en el caso de ciertas poblaciones septentrionales: cf. J. Santos, «El poblamiento romano en el área de los autrigones, caristios, várdulos y vascones. Estado actual de la investigación y perspectivas", Congreso de Historia de Euskal Herria. I: De los orígenes a la cristianizaciómn, Bilbao 1987, pp. 217 y ss., especialmente pp. 217-224 con respecto a la identificación de las civitates.

72 Por desgracia esta vía de investigación requeriría el paso de muchos años, así como una labor ingente, que conllevaría, además de un estudio toponímico de cada una de las regiones, un plan interdisciplinar de prospecciones arqueológicas, centrado en el estudio de las vías de comunicación, los centros de aprovechamiento aurífero y los núcleos de población de época romana. 
Tales enclaves de poblamiento serían utilizados en muchas ocasiones más como simples centros de descanso ${ }^{73}$ que como residencias permanentes de los individuos que aportaban su fuerza de trabajo en dichas tareas.

Con estos objetivos, además de los emplazamientos tradicionales castreños, cuyo número aumentaría y se reforzaría, a la par que se transformaría (aunque parcialmente), en época romana altoimperial, al tiempo que sus estructuras constructivas serían remodeladas por influencia romana ${ }^{74}$ (aportación de soluciones arquitectónicas, como la construcción de las esquinas o el abovedamiento), quizás haya que buscar salida a las nuevas necesidades creadas en cuanto a los indígenas del Suroccidente asturiano en la existencia de reductos de población que diferían de los propios de la cultura castreña.

Ante todo un cierto número de tesos existentes en el ámbito territorial de ciertas explotaciones mineras de oro, o ubicados en lugares muy próximos a las mismas $^{75}$, no resolverían más que parcial y temporalmente dicho problema: casi todos ellos tendrían su origen como consecuencia de las labores de removida y desmonte de las zonas mineralizables, lo que ocasionaría un complejo sistema de fosos, aprovechados en la configuración de dichos establecimientos.

Por otra parte las propias necesidades de alojamiento de la mano de obra exigirían la presencia de un poblamiento abierto, que se conformaría a base de barracones o tendejones de madera, así como aprovechando otra clase de construcciones levantadas con ese mismo material (cobertizos) ${ }^{76}$.

Este tipo de construcciones parece haber arraigado por ejemplo de forma mayoritaria en algunas zonas del concejo de Allande, en las que hasta la fecha no ha sido posible detectar recintos castreños en el entorno de un número abundante de explotaciones mineras de oro (tal y como cabría esperar no sólo por su cantidad sino también por el volumen de terreno aurífero removido).

Las regiones de implantación de esta forma de hábitat se pueden identificar igualmente con el valle del Arganza (también en la parte de su recorrido por el concejo de Cangas del Narcea), y de manera más evidente aún en el distrito minero del río del Oro y el Valledor ${ }^{77}$, o incluso en el Puerto del Palo-Montefurado, sobresaliendo en todo caso los existentes en la zona minera de Bustantigo ${ }^{78}$.

${ }^{73}$ En cuyo caso cumplirían las funciones propias de edificios-dormitorios, de uso temporal escaso (apenas las horas nocturnas).

74 J. L. Maya, «La cultura castreña asturiana: su etapa romano-provincial», p. 238 (mapa).

75 Cuyo origen (y construcciones) remontan a tiempos romanos como resultado de esas mismas actividades laborales.

${ }^{76}$ F. J. Sánchez-Palencia y M. ${ }^{a}$ D. Fernández-Posse, «Poblamiento y minería prerromana y romana en el Noroeste peninsular», Indígenas y romanos en el Norte de la Península Ibérica, San Sebastián 1993, pp. 201 y ss.

77 Destacan, entre otros, los asentamientos antiguos en torno a Villalaín y Robledo como exponentes de lugares de alojamiento de la mano de obra destinada al aprovechamiento de las grobas (fanas) de color rojizo de la región.

${ }^{78}$ N. Santos, «La vía romana de Berducedo a Bustantigo en el concejo de Allande (Asturias)», Gerión 20 (2002), 372 y ss. 
A este respecto no debemos olvidar que las propias actividades mineras vinculadas con las ingentes labores y técnicas hidráulicas utilizadas en el desmonte de los terrenos auríferos originarían una serie de fosos, aprovechados para configurar núcleos de poblamiento similares a los castreños: se daría origen así a las coronas, cuyos exponentes más claros se encuentran entre los astures de la región leonesa (Corona de Corporales en Truchas por ejemplo), aunque dispongamos igualmente de indicios de su presencia en el Suroccidente asturiano ${ }^{79}$.

\section{HÁBITAT CASTREÑO Y PRESENCIA ROMANA}

Es en este contexto en el que podemos afirmar que, desde una fecha bastante temprana, aparecen síntomas de que algunos de los recintos de población indígena serían habilitados por los romanos como núcleos de asentamiento de ciertos destacamentos militares.

Una de las primeras referencias de la documentación escrita la encontramos en Dión Casio ${ }^{80}$, quien nos asegura que, en el ámbito temporal de las guerras astur-cántabras correspondientes a las actividades militares dirigidas por Publio Carisio, el legado de Augusto logra abortar con cierta facilidad uno de los levantamientos de los astures una vez que consigue rechazarlos «de un lugar fortificado que estaban asediando", posiblemente uno de los antiguos recintos de población castreña que, habitado en un principio por población indígena, habría pasado a convertirse con posterioridad en uno de los enclaves militares romanos ${ }^{81}$.

Si tomamos como punto de referencia un territorio concreto del Suroccidente de Asturias, como por ejemplo el correspondiente en la actualidad al concejo de Allande, observaremos que durante la etapa altoimperial cada uno de los trazados de la red viaria en vigencia durante aquellos años dispondría de uno de tales enclaves, ocupado y controlado por destacamentos militares poco numerosos ${ }^{82}$.

Tales asentamientos poblaciones (en su origen de carácter indígena) estaban destinados a adquirir una marcada impronta militar y a vincularse directamente con los centros de hábitat de la cultura castreña que ofrecían mejores condiciones estratégico-territoriales, al tiempo que se hallarían en conexión con los nudos de co-

79 Más detalles en C. Domergue, «Les mines d'or du Nord-ouest de l'Espagne. Les coronas, technique d'exploitation ou hábitat? », Papers in Iberian Archaeology, Oxford 1984, pp. 370 y ss.

80 Historia Romana 54.5.3: «Los astures por su parte, tan pronto como fueron rechazados de un lugar fortificado que estaban asediando y, con posterioridad, fueron vencidos en un combate, no continauron ya la sublevación y se sometieron rápidamente».

81 N. Santos, «Publio Carisio y las guerras astur-cántabras», BIDEA, n. ${ }^{\circ} 104$ (1981), 851-852. Cf. igualmente «La romanización de los astures meridionales: un ejemplo característico», Homenaje a $A$. Galmés, Oviedo-Madrid, 1985, 2, pp. 189 y ss.

82 No debemos olvidar a este respecto que el término castro tiene origen latino, y deriva de la similitud existente, en cuanto a sus estructuras, entre el contorno de los campamentos romanos (castra) y los elementos que definen la tipología de los recintos fortificados de las poblaciones indígenas del Norte peninsular. Cf. J. L. Maya, «Hábitat y cronología de la cultura castreña en Asturias», Portugalia, 4-5 (1983-1984), 175 y ss. 
municación más significativos y se erigirían en centros de afluencia y recepción de los productos auríferos obtenidos en los yacimientos mineros correspondientes a cada uno de los distritos con vistas a su evacuación hacia la capital del Imperio.

Como ejemplos más representativos cabe recordar, entre otros, el papel desempeñado por el recinto poblacional de San Chuis, enclavado en la margen izquierda del río Arganza; dicho centro de población astur-romano estaría destinado sin duda a cumplir unas funciones similares a las de uno de los dos centros fortificados de Besullo (en el concejo de Cangas del Narcea) con respecto a la margen derecha de esa misma corriente fluvial ${ }^{83}$.

En síntesis, es posible afirmar que los asentamientos poblacionales de nueva creación, a cuyo origen contribuiría en buena medida el descubrimiento y explotación de nuevos yacimientos mineros, así como el desplazamiento de un colectivo amplio de personas para prestar su fuerza de trabajo en los mismos, imitarían las formas de construcción castreñas que venían utilizándose tradicionalmente, lo que no impediría la adaptación y aplicación de las técnicas romanas constructivas ${ }^{84}$.

Ahora bien, como resultado de las continuas y abundantes actividades desplegadas en las cortas mineras de oro se produciría un cambio brusco en cuanto al proceso de producción de las poblaciones indígenas del Suroccidente de Asturias: aunque no tendría lugar un debilitamiento acusado del sector ganadero, que hasta época romana había sido prioritario entre dichas comunidades, la preeminencia pasaría, a partir de mediadosfinales del siglo I d.C., al sector y actividades vinculadas a la minería ${ }^{85}$.

\section{INTEGRACIÓN INDÍGENA EN EL CONTEXTO POBLACIONAL ROMANO}

La presencia de contingentes de población extraña a los astures (bien fuesen militares o mano de obra libre asalariada) acarrearía un arraigo y desarrollo de la propiedad privada, debilitándose y acabando por desaparecer casi de manera definitiva los lazos de tipo comunitario que habían venido caracterizando durante los siglos anteriores las estructuras económicas de la población castreña.

Tomando como base estas alteraciones económicas es posible afirmar que se derivarían para los indígenas de la región toda una serie de consecuencias y cambios de índole socio-política a lo largo del Alto Imperio ${ }^{86}$.

${ }^{83}$ En el mismo contexto se explican los objetivos que cumpliría uno al menos de los dos poblados fortificados antiguos existentes en los alrededores de Berducedo, igualmente en el concejo allandés.

84 Este tipo de poblamiento favorecería la pervivencia de las estructuras sociales de la organización castreña, así como la débil integración de dichas comunidades en la organización romana. Cf. M. Vigil, «Romanización y permanencia de estructutras sociales indígenas en la España septentrional», $B R A H$ 152 (1963), 225 y ss.

85 Teniendo en cuenta que los beneficios obtenidos de dichos recursos económicos no revertirían en ningún caso directamente sobre los integrantes de dichas comunidades.

86 De forma mucho más acusada durante el siglo II que en el transcurso del I. 
En este sentido la administración romana aceptaría, y potenciaría de buen grado, las formas de hábitat típicamente indígenas (poblados fortificados o recintos castreños), puesto que esto no entorpecería sus intereses político-administrativos (control y organización del territorio) ni sus objetivos económicos.

La realidad histórica parece contrastar con las palabras de Floro ${ }^{87}$ en el sentido de que, entre las medidas tomadas por el primer emperador romano tras la finalización de las guerras astur-cántabras, destaca el asentamiento de las poblaciones indígenas septentrionales en zonas llanas.

Tal vez lo que el historiador latino quiere expresar no sea más que el proceso de integración de sus componentes en el marco de la organización político-administrativa romana, puesto que este tipo de hábitat, que se asimila con núcleos de carácter militar/campamental, constituiría los lugares de población en los que tendría acogida la asamblea del pueblo ${ }^{88}$.

A este respecto disponemos en el Suroccidente asturiano de un documento preciso en el que se nos confirma la capitalidad de la población que habitaba dicha región en tiempos prerromanos y romanos, los pésicos: a través de la lápida encontrada en Arganza (concejo de Tineo), cuyo campo epigráfico (TVTELA[E]/ $C$ (ivitatis) $P$ (aesicorum)/ PLACID/ VS PLACIDI/ VS EX VOTO) nos documenta la existencia de un centro administrativo-territorial en torno al cual se articulaba el territorio propio de dicha comunidad, se comprende el marco en el que se llevaría a efecto el proceso de integración en el modelo romano por parte de las poblaciones septentrionales hispanas ${ }^{89}$.

De acuerdo con esto resulta posible afirmar que la existencia de recintos de población castreña que dispondrían de destacamentos militares de mayor o menor entidad en su interior tal vez haya que ponerla en relación en su origen con el proceso de municipalización del territorio ocupado por las poblaciones indígenas del Suroccidente de Asturias (San Chuis, Besullo, Berducedo, Bustantigo, Arganza...).

87 Compendio de historia romana 2.33.58-59: «Tal fue el final de las campañas de Augusto y también de la recuelta de Hispania; su fidelidad fue asegurada al punto, lo mismo que una paz eterna, gracias al cambio sobrevenido en el temperamento mismo de sus habitantes, desde entonces más dispuestos a llevar una vida pacífica, así como a las medidas tomadas por Augusto: temiendo la confianza que les inspiraban sus montes, refugio seguro para ellos, les obligó a habitar y vivir en el emplazamiento de su campamento, puesto que estaba en el llano: además, que allí (se refiere a los campamentos romanos establecidos en el llano) se reuniera el consejo de la gente (consilium gentis), que pasaría a ser considerado como su capital».

88 Convirtiéndose simultáneamente en capitalidad de los diferentes grupos o comunidades. Más detalles en C. Nicolet, L'inventaire du monde. Géographie et politique aux origins de l'Empire romain, París 1988.

89 El dedicante de dicho monumento quizás pueda ser identificado con un minero de las explotaciones auríferas próximas al lugar en que se descubrió la lápida, sobre todo si tenemos en cuenta que su onomástica (Plácido Placidio), aunque en ocasiones alterada (Placidio Plácido), se atestigua con relativa frecuencia en el ámbito nordoccidental peninsular (CIL II 2.523; 2.469; 2.655: 2.640; 4.394; 5.637...). Cf. N. Santos, El ejército romano y la romanización de los astures, pp. 242-243 y «La inscripción de Arganza (Tineo) y la población de los pésicos entre los astures transmontanos», Lancia 5 (2002-2003), 167 y ss. 
En este contexto se puede comprender mucho mejor la afirmación de Floro, quien asegura que en dichos centros, de carácter militar, los componentes de los grupos sociales suprafamiliares celebraban tanto sus reuniones políticas como las asambleas destinadas a supervisar el funcionamiento administrativo-territorial de los diferentes poblados ${ }^{90}$.

Por ello cada una de las vías de comunicación más significativas del Suroccidente asturiano dispondría, durante el Alto Imperio al menos, de uno de estos núcleos, que al mismo tiempo contarían con toda una serie de elementos destacados:

- ante todo su situación estratégico-territorial, que revestía unos caracteres especiales, dominando un espacio de suelo amplio;

- además servir de lugar de acogida a grupos de militares (cuyo número no sería muy amplio) encargados del control del territorio respectivo;

- igualmente su función como centro de recepción de los productos obtenidos en los diferentes distritos mineros de aprovechamiento del oro;

- a continuación su vinculación directa con alguna vía de comunicación de gran importancia económica y alcance geoestratégico ${ }^{91}$; y,

- por último, su realce como centro administrativo para un grupo de población más o menos amplia.

Tal vez sea posible pensar a este respecto que, a medida que avanzamos en la segunda mitad del siglo I del Imperio, el espíritu rebelde de los indígenas astures en general se iría suavizando y debilitando paulatinamente como consecuencia de su integración en el marco de la organización político-administrativa romana.

A este proceso contribuiría, además de su presencia y enrolamiento en las unidades militares romanas como tropas auxiliares, su participación en las actividades económicas vinculadas a la minería del oro durante el Alto Imperio92.

90 Pasando a convertirse dichos enclaves en capitalidades de cada una de las regiones, al tiempo que el territorio circundante se organizaría en torno a ellas.

${ }^{91}$ Cuando estos mismos núcleos de hábitat no eran centros de confluencia de caminos de gran significado (nudos de comunicación). Cf. C. Fernández Ochoa, «El impacto romano sobre el hábitat del Noroeste», BIDEA 120 (1986), 1099 y ss.

92 Lo que supondría para algunos componentes de dichas comunidades una especie de promoción social, o al menos su inclusión en un proceso de diferenciación social cada vez más acusado. 


\section{APÉNDICE I}

Catalogación de los castros asturianos por concejos

- Allande:

- Aller:

- Amieva:

- Avilés:

- Bimenes:

- Boal:

- Cabrales:

- Cabranes:

- Candamo:

- Cangas de Onís:

- Cangas del Narcea:

- Caravia:

- Carreño:

- Caso:

- Castrillón:

- Castropol:

- Coaña:

- Colunga:

- Corvera:

- Cudillero:

- Degaña:

- El Franco:

- Gijón:

- Gozón:

- Grandas de Salime: 3

- Grado:

- Ibias:

- Illas:

- Illano:

- Langreo:

- Las Regueras:

- Laviana:

- Lena:

- Llanera:

- Llanes:

- Mieres:

- Miranda:

- Morcín:

- Muros del Nalón:

- Nava:

\section{J. M. González Nuevos inventarios}

12

7

0

0

1

3

5

5

1

1

1

3

1

21

1

1

1

2

1

2

7

3

2

1

2

1

6

3

3

5

10

3

0

2

2

3

2

12

5

0

6

1

1

0

1
5

10

9

5

6

4

4

3

15

2

6 
- Navia:

4

- Noreña:

0

- Onís:

- Oviedo:

- Parres:

- Peñamellera Alta:

- Peñamellera Baja:

- Pesoz:

- Piloña:

- Ponga:

- Pravia:

- Proaza:

- Quirós:

- Ribadedeva:

- Ribadesella:

- Ribera de Arriba:

- Riosa:

- Salas:

- San Martín Oscos:

- San Martín del Rey Aurelio:

- San Tirso de Abres:1

- Santa Eulalia de Oscos:

- Santo Adriano:

- Sariego:

- Siero:

- Sobrescobio:

- Somiedo:

- Soto del Barco:

- Tapia de casariego:9

- Taramundi:

- Teverga:

- Tineo:

- Valdés:

- Vegadeo:

- Villanueva Oscos:

- Villaviciosa:

- Villayón:

- Yernes y Tameza:

0 16

0

0

0

2

2

1

4

2

0

0

5

2

9

0

0

3

1

2

0

5

1

2

0

11

2

4

20

8

0

1

7

1

0
6

1

3

7-9

4

5

9

6

5

2

4

1

2

8-9

4

2

10

S. Ríos y C. García de Castro, Asturias castreña, Gijón 1998, pp. 24-27. 


\section{APÉNDICE II}

\section{Índice de los yacimientos castreños de Asturias}

\section{CASTROS DEL SECTOR ORIENTAL}

1. La Barquerona, Argüero (Villaviciosa)

2. La Atalaya, Tazones (Villaviciosa)

3. El Campón, Olivar (Villaviciosa)

4. La Corolla, Ambás (Villaviciosa)

5. El Castiello, Camoca (Villaviciosa)

6. Picu Castiello, Moriyón (Villaviciosa)

7. El Castiello, Acebo (Sariego)

8. La Pica el castro, Aramanti (Sariego)

9. Castiello el Peñón, Barbecho (Sariego)

10. La Isla, Colunga

11. El Castiello, La Riera (Colunga)

12. Castro Villeda, San Juan (Colunga)

13. Castiello, Castiello de Arriba (Colunga)

14. El Picu el Castro, Caravia

15. El Cuetu, Llano (Cangas de Onís)

16. El Picu Mancobio, Arriondas (Parres)

17. La Punta la Torre, Llanes

18. La Corona el Castro, Hería (Nava)

19. Castiello de Sales, Polanova (Nava)

20. El Castiello, Taranes (Ponga)

21. La Corona del Castro, San Andrés (Sobrescobio)

22. La Corona, Campiellos (Sobrescobio)

23. El Pico los Castiello, Campo de Caso (Caso)

D1. El Castiello, Casería de Piñares (Villaviciosa)

D2. Monte Viyao, Borines (Piloña)

D3. Castro de Llía, Alles (Peñamellera Alta)

D4. La Forcá, Bioves (Nava)

D5. La Capilla, Pivierda (Colunga)

\section{CASTROS DEL SECTOR CENTRAL}

24. El Castrillón, Pola de Laviana

25. El Cerco, La Pumará (Laviana)

26. El Corón, La Aldea (Laviana)

27. El Picu castiello, La Rionda (Laviana)

28. El Picu Castillu, Pumarín (Laviana)

29. El Picu Castiello, Melendreros (Bimenes)

30. El Picu Castiechu, Cabezón (Lena)

31. El Curucho, Reconcos (Lena) 
32. El Castiechu las Coronas, Tiós (Lena)

33. El Castiello, Sorribas (Lena)

34. El Curucho, Tiós (Lena)

35. El Questru y Pena el casticho, Jomezana de Arriba (Lena)

36. El Pico Casticho, Malvedo (Lena)

37. El Questru, Otero (Lena)

38. El Picu, Los Campos (Lena)

39. Les Mueles, Llanos (Aller)

40. El Questru, Moreda (Aller)

41. Los Castiechos, Pola del Pino (Aller)

42. El Castiechu, Felechosa (Aller)

43. La Llana el Rebuyu, El Collado (Mieres)

44. El Cuitu Castiello, Villandio (Mieres)

45. Peña Tayá, Requejado (Mieres)

46. El Cantu Riba, Rozadiella (Mieres)

47. El castiello, Sarabia (Mieres)

48. El Pico Escucha, Armiello (Mieres)

49. Picu Pumardongo, Pumardongo (Mieres)

50. Recastiello, Gallegos (Mieres)

51. Castiello de Lladreo, La Villa (Mieres)

52. El Picu Castiello, El Collao (Riosa)

53. El Picu Llera, Peñanes (Morcín)

54. El Castiello, Fozana (Siero)

55. El Pico Castiello, La Collada (Siero)

56. El Cuetu, San José (Siero)

57. El Cuitu, El Castiello (Siero)

58. El Castiello, Marcenado (Siero)

59. El Cutu la Pila, Alperi (Oviedo)

60. Grandota, Grandota (Oviedo)

61. El Picu el Cogollu, Las Cuestas (Oviedo)

62. El Pico Castiello, Perlín (Oviedo)

63. Monte Alto, El Monte (Oviedo)

64. La Cogolla, La Carisa (Oviedo)

65. El Picu, Cuyences (Oviedo)

66. El Castiello, Villaperi (Oviedo)

67. El Pico Castiello, Quintana (Oviedo)

68. El Castro, Priañes (Oviedo)

69. La Planadera, San Claudio (Oviedo)

70. El Castiellu, Llagú (Oviedo)

71. Peña Constancio, Las Carangas (Santo Adriano)

72. El Cantu el Arbeyal, Serandi (Proaza)

73. La Cogolla y Cogollina, castro (Teverga)

74. La Garba, berrueño (Teverga)

75. La Picona, Ricabo (Quirós)

76. Cochao Castro, Villamarcel (Quirós)

77. San Juan, Llanuces (Quirós) 
78. El Picu la Corona, Picu Llanza (Ribera de Arriba)

79. El Picu la Viña, Santa Eulalia (Ribera de Arriba)

80. El Cueto, Caraviés (Ilanera)

81. La Cogolla, Seberies (Llanera)

82. El Cantu San Pedro, Lugo (Llanera)

83. La Coroña, Les Areñes (Llanera)

84. Campa Torres, Jove (Gijón)

85. El Castiellu, Serín (Gijón)

86. El Cuetu, San Andrés (Gijón)

87. El Cantu la Figal, Nieva (Gozón)

88. El Castiellu, Molín del Puertu (Gozón)

89. Los Garabitales, Granda (Gozón)

90. La Barrera, Logrezana (Carreño)

91. El Castro, Huerno (Carreño)

92. El Pico Castiello, Molleda (Corvera)

93. El Lugar, Juncedo (Corvera)

94. La Peñona, San Amaro (Castrillón)

95. El Castiello, La Mortera (Candamo)

96. El Campón, La Carcabina (Muros del Nalón)

97. El Castillo de San Martín, Soto del Barco

98. La Pica el Castro, Villar (Candamo)

99. El Pico Ruedes, Valsera (Las Regueras)

100. El Castiello los Vallaos, Paladín (Las Regueras)

101. El Castiello, Ambás (Grado)

102. El Cascayal, Berció (Grado)

103. El Castiellu el Pedreu, Cabruñana (Grado)

104. Castrofabeiro, Vigaña (Grado)

105. El Castiechu, Llamarda (Somiedo)

106. La Cavona, Lamuño (Cudillero)

107. El Curión, La Fenosa (Cudillero)

108. El Castro, Cudillero

109. La Garita, Oviñana (Cudillero)

110. El Cogollo, El Caliero (Pravia)

111. Las Cogollas, Linares (Salas)

112. El Castiello, Doriga (Salas)

113. El Castro, Alava (Salas)

114. Penaguda, Boinás (Belmonte)

115. El castro, Vigaña (Belmonte)

116. El Castro, Ondes (Belmonte)

D6. La Cogolla, La Corca (San Martín del Rey Aurelio)

D7. Las Segadas, El Cantiquín (Mieres)

D8. El Fresno, Fresno (Llanera)

D9. La Armada, Armada (Castrillón)

D10. El Barrial, Corros (Castrillón)

D11. El Castro, Quiloño (Castrillón)

D12. El Picu el Castru, La Peñuca (Pravia) 


\section{CASTROS DEL SECTOR OCCIDENTAL I}

117. El Castiechu, Caleila (Valdés)

118. El Castiechu, Cerezal (Valdés)

119. Peña Castiel, Chano de Luarca (Valdés)

120. La Cogocha, Canero (Valdés)

121. El Cerco de los Moros, La Llamiella (Valdés)

122. El Castro, Oré (Valdés)

123. El Castro, Zardaín (Tineo)

124. El Castro, Villatresmil (Tineo)

125. El Castro (El Pico del Castro), Tineo

126. El Castiechu, Bustiello (Tineo)

127. La Mouta, Villameana (Tineo)

128. El Cuernu el Chobo (La Pena el Molín), Villameana (Tineo)

129. El Pico los Moros, Valentín (Tineo)

130. El Castillo de Manxelón, Naraval (Tineo)

131. El castiecho, Veiga (Tineo)

132. Las Torres (Los Castros), Riocastiello (Tineo)

133. El Castrón, Barredo (Tineo)

134. Fumulín, Castañera (Tineo)

135. El Castillo, veneiro (Tineo)

136. El Castillo de los Moros, Agüera de Carriles (Tineo)

137. El Castiechu (El Castro), Luciernas (Tineo)

138. El Castro (Pico Rendión), Truébano (Tineo)

139. El castro, Fresno (Tineo)

140. El Pico San Pedro, Perluces (Tineo)

141. El Castro, Perluces (Tineo)

142. El Castro (El Palacio), Figueras (Allande)

143. El Castiechu, Pradiella (Allande)

144. El Castro (El Cuturuyón), Collada (Allande)

145. Castrp Piqueiros, Tremado (Allande)

146. El Castro, San Martín del Valledor (Allande)

147. El Pico San Chuis, San Martín de Beduledo (Allande)

148. El Pico el Castro, Arbeyales (Allande)

149. El Castiecho, Carcedo (Allande)

150. La Garganta, Castro (Allande)

151. El Pico Castiello, Berducedo (Allande)

152. El Castro, Adralés (Cangas del Narcea)

153. Los Castros, Ridera (Cangas del Narcea)

154. La Pena el Castiechu, Otardesú (Cangas del narcea)

155. El Pico Sieiro, La Linde (Cangas del Narcea)

156. Las Corradas, Otriello (Cangas del Narcea)

157. El Tesu la Cochada, Bimeda (Cangas del Narcea)

158. Las Torres, Vega de Castro (Cangas del Narcea)

159. Los Castillos, Vallado (Cangas del Narcea)

160. Los Castros, Villar de los Indianos (Cangas del Narcea) 
161. La Plaza de los Moros, Llanos (Cangas del Narcea)

162. El Castiello, Corias (Cangas del Narcea)

163. El Castro, Larón (Cangas del Narcea)

164. El Castiechu, Pixán (Cangas del Narcea)

165. El Castiechu, Naviego (Cangas del Narcea)

166. El Tesu los Castros, Villar de Rengos (Cangas del Narcea)

167. El Castro, Posada de Rengos (Cangas del Narcea)

168. El Castro, Acio (Cangas del Narcea)

169. El Chanu las Coronas, Castiello (Cangas del Narcea)

170. El Castiechu, Valcabo (Cangas del Narcea)

171. El Castiello, Tebongo (Cangas del Narcea)

172. El Castro, Trones (Cangas del Narcea)

173. Los Castiellos, Rengos (Cangas del Narcea)

174. O Castelo, Sena (Ibias)

175. El Castelo, Cecos (Ibias)

176. El Castelo, San Clemente (Ibias)

177. Los Castros, Degaña

243. La Porida, Trevías (Valdés)

244. Trichamuela, Porley (Cangas del Narcea)

245. Las Torres, Tremado de Carballo (Cangas del Narcea)

246. O Coredo, A Lagúa (Ibias)

D13. (Muñas de Abajo)

D14. (Arcayana la Vieya)

D15. (La Mafaya)

\section{CASTROS DEL SECTOR OCCIDENTAL II}

178. El Castelo (Esteiro), Campos (Tapia)

179. Castro Coronas, El Pico (Tapia)

180. Castillos de Pereira, Acevedo (Tapia)

181. El Picón, Campos (Tapia)

182. El Corcovón, Acevedo (Tapia)

183. Las Cercas, Castrovaselle (Tapia)

184. Peña Caldeira, La Veguina (Tapia)

185. Campo San Lorenzo, Santa Águda (Tapia)

186. El Castelón, Serantes (Tapia)

187. El Toxal, Tapia

188. Castreda, Balmorto (Tapia)

189. El Castello, Rondello (Tapia)

190. Punta da Figueira, Coaña

191. El Castelón, Coaña

192. El Monte el Castro, Mohías (Coaña)

193. Os Castros, castro (San Tirso)

194. As Croas, Salcido (San Tirso)

195. As Croas, Eilale (San Tirso) 
196. Molexón, Vegadeo

197. Os Castros, Pruida de Meredo (Vegadeo)

198. El Castro, Castro (Taramundi)

199. Os Castros, Taramundi

200. El Pico el Castro, Pelou (Grandas de Salime)

201. El Chao San Martín, Grandas de Salime

202. El Castro, Vilabilleiro (Grandas de Salime)

203. La Pena el Castro, Trabada (Grandas de Salime)

204. El Castro, Deilán (San Martín de Oscos)

205. El Pico da Mina, Bousoño (San Martín de Oscos)

206. El Castro, Lineras (Santa Eulalia de Oscos)

207. Los Castros, Ferreira (Santa Eulalia de Oscos)

208. La Llomba del Castro, Llombatín (Illano)

209. Los Castelloes, Sarzol (Illano)

210. El Castelón, Cedemonio (Illano)

211. El Castellón, Illano

212. El Castelo, Villar de San Pedro (Boal)

213. El Castrillón, Vega de Ouria (Boal)

214. El Castro, Pendia (Boal)

215. El Castro, Los Mazos (Boal)

216. El Castro, La Escrita (Boal)

217. El Castro, Illaso (Villayón)

218. El Castrillón, Andés (Navia)

219. Los Castiellos, Piñera (Navia)

220. El Castro, Puerto de Vega (Navia)

221. El Castiel, Soirana (Navia)

222. La Santa Olalla, Villanueva (Navia)

223. El Castro, Villanueva (Navia)

224. El Castiello, Ponticiella (Villayón)

225. El Castro, Pesoz

226. San Isidro, Oesoz

227. Los Castros, Viladevelle (Castropol)

228. Los Castros, Castro (Castropol)

229. El Corno, Villadún (Castropol)

230. La Corona, Iramola (Castropol)

231. Os Castros, Bouza (Castropol)

232. O Corolo, Lantoira (Castropol)

233. O Castelo (Os Castros), Lagar (Castropol)

234. Los Castros, Brul (Castropol)

235. Os Castros, Seares (Castropol)

236. Os Castros, Santalla (Castropol)

237. Cabo Blanco, Valdepares (El Franco)

238. El Castellón, Miudes (El Franco)

239. El Castellón, La Caridad (El Franco)

240. El Castrón, Andina (El Franco)

241. La Corona, Arancedo (El Franco) 
242. La Corona, San Juan de Prendones (EI Franco)

A. Fanjul Peraza, Los castros de Asturias. Una revisión territorial y funcional, Teverga 2005, pp. 25-35.

\section{APÉNDICE III}

\section{Castros romanizados y minería romana del oro en Asturias}

1. El Picón de La Corona (Campos y Salave, Tapia de Casariego)

2. Los Castros de Brul (Castropol)

3. Salave (Tapia de Casariego)

4. El Castello de Salave (Tapia de Casariego)

5. Cabo Blanco (El Franco)

6. Las Coronas de la Roda (Tapia de Casariego)

7. Los Castillos de Pereira (Tapia de Casariego)

8. Valdepares (EI Franco)

9. El Castelón de La Caridad (El Franco)

10. El Castelón de Miudes (El Franco)

11. Carcobas de Miudes (El Franco)

12. La Corona de San Juan (Prendones, El Franco)

13. La Braña (El Franco)

14. La Andina - Arancedo

15. La Corona del Castro (Arancedo (El Franco)

16. Las Cercas de Castrovaselle (Tapia de Casariego)

17. Veguiña

18. El Castrillón de Coaña

19. El Cabrucal de Arbón (Navia)

20. Vega de Ouria (Boal)

21. Brañalibre - Peña de la Barreira (Bobia, Boal)

22. El Castelo de Villar de San Pedro (Boal)

23. El Castillón (Vega de Ouria, Boal)

24. La Porida de Llendecastiello (Trevías, Valdés)

25. Trevías - Paredes (Valdés)

26. El Cerco los Moros (La Llamiella, Valdés)

27. Naraval (Tineo)

28. Castillo Veneiro (Calleras, Tineo)

29. El Pico Cortino (Folledo-Navelgas, Tineo)

30. Navelgas (Tineo)

31. Fornones (Tineo)

32. El Castro de Fresnedo (Zardaín, Tineo)

33. Los Castros de Riocastiello (Tineo)

34. Santiago de Cerredo (Tineo)

35. Lavadoira (Tineo)

36. El Pico San Roque de Perluces (Pozón, Tineo) 
37. El Castillo los Moros de Agüera (Arganza, Tineo)

38. El Castro de Arganza (Tineo)

39. Arganza (Tineo)

40. Carcoas de Cereceda, Figueras, La Sienra y Presnedo (Allande)

41. Puerto del Palo, Montefurado, Cueva de Xuan Rata, Fana la Freita (Allande)

42. El Cuturuyón de San Pedro (Lago, Allande)

43. Lago (Allande)

44. Castello de Berducedo (Allande)

45. Carcabón de Oruga (Allande)

46. La Garganta de Castro (Berducedo, Allande)

47. El castiecho de Villagrufe (Allande)

48. El Pico San Chuis (Beduledo, Allande)

49. Iboyo (Allande)

50. El Castro de Trones (Cangas del Narcea)

51. Besuyo - Faidiel (Cangas del Narcea)

52. San Félix y Pozo de las Montañas (Cangas del narcea)

53. Vegalagar (Cangas del Narcea)

54. Límite entre San Antolín y Cecos (Ibias)

55. San Antolín (Ibias)

56. El Castelo de Cecos (Ibias)

57. Valabelleiro (Grandas de Salime)

58. El Cuturulu de Valabelleiro (Grandas de Salime)

59. El Chao Samartín (Grandas de Salime)

60. Corralín - La Muracal (degaña)

61. El castro de Larón (Cangas del Narcea)

62. Begega (Belmonte)

63. Ablaneda (Salas)

64. Pico Castiello de Pedrero (Bimenes)

65. San Emeterio de Bimenes

J. L. MAYA, «La cultura castreña asturiana: su etapa romano-provincial»,

Lancia 1 (1983) 230

\section{APÉNDICE IV \\ Castros romanizados y villae en Asturias}

1. Castelo de Calambre o del Esteiro (Tapia)

2. La Corona del Castro (Arancedo, El Franco)

3. El Monte del Castro (Mohías, Coaña)

4. El Castellón (Coaña)

5. El Castro de Pendia (Boal)

6. El Castro de La Escrita (Boal)

7. El Castro de Manxelón (Tineo)

8. El Pico San Chuis (Allande)

9. El Pico Castello de Berducedo (Allande) 
10. Santa Cruz (Pesoz)

11. El Chao San Martín (Grandas de Salime)

12. El Castro de Larón (Cangas del Narcea)

13. Las Torres de Vega de Castro (Cangas del Narcea)

14. El Castro de Tremado de Carbayo (Cangas del Narcea)

15. El Castiello de Doriga (Cornellana, Salas)

16. El Castro de Doña Palla (Pravia)

17. La Magdalena de la Llera (Santianes, Pravia)

18. Murias de Ponte (Soto del Barco)

19. El Castillo San Martín (Soto del Barco)

20. La Armada de la Plata (Castrillón)

21. Pico Castiello de Molleda (Corvera)

22. Bañugues (Gozón)

23. Muria Llazana (Las Regueras)

24. Andallón (Las Regueras)

25. El Castillo de los Vllaos (Las Regueras)

26. Peña Castiello de Boanga (Oviedo)

27. La Planadera (San Claudio, Oviedo)

28. La Cogolla de Fitoria (Oviedo)

29. El Castiellu de Llagú (Oviedo)

30. Muries de Paraxuga (Oviedo)

31. Monte les Muries (Siero)

32. Villarmosén (Oviedo)

33. Lillo (Naranco, Oviedo)

34. La Corona del Picu Llanza (Ribera de Arriba)

35. El Pico Castiello de Collao (Riosa)

36. Castiello de Bustiello (Mieres)

37. Pico Casticho de Cabezón (Lena)

38. Santa María de Castiecho (Lena)

39. Villa Memorana (Lena)

40. El Curucho de Campos (Lena)

41. Pico Castiello de Pedrero (Bimenes)

42. El Canto San Pedro (Siero?)

43. Pico Castiello de La Collada (Siero)

44. Muries de Beloño (Cenero, Gijón)

45. Tacones (Gijón)

46. Ería de San Miguel (Gijón)

47. Fano (Gijón)

48. Natahoyo (Santa Olaya, Gijón)

49. Campa Torres (Gijón)

50. Aroles (Gijón)

51. Campo Valdés (Gijón)

52. Ceares (Contrueces, Gijón)

53. Puelles (Villaviciosa)

54. Rodiles (Villaviciosa)

55. El Castiello de La Riera (Colunga) 
56. La Isla (Colunga)

57. Ribadesella

58. Vega de Poja (Sariego)

59. Tamayanes (Tineo)

60. El Castrillón de Raíces (Castrillón)

61. Castello de Bardascón en Salave (Tapia)
A. Castro de Piñera (Castropol)
B. Castrovaselle (Tapia)
C. Castro de Illano
D. La Garganta (Allande)
E. Castillo Veneiro (Calleras, Tineo)
F. El Castro de Adralés (Cangas del Narcea)
G. La Picona de Ricabo (Quirós)
H. Peña Tayada (El Vescón, Mieres)
I. Les Mueles de Santibáñez (Aller)
J. Pico Castiello de Miravalles (Villaviciosa)
K. El Picu'l Castro (Caravia)

J .L. MAYA, «La cultura castreña asturiana: su etapa romano-provincial», Lancia 1 (1983) 228. 